\title{
Lehmien ontumisen mittaus langattomalla kiihtyvyysanturilla
}

\author{
Matti Pastell ${ }^{1,2)}$, Johannes Tiusanen ${ }^{1)}$, Mikko Hakojärvi ${ }^{1)}$ ja Laura Hänninen ${ }^{2,3)}$ \\ ${ }^{1)}$ Helsingin yliopisto, Agroteknologian laitos, PL 28, 00014 Helsingin Yliopisto, \\ etunimi.sukunimi@helsinki.fi \\ $\left.{ }^{2}\right)$ Helsingin yliopisto, Eläinten hyvinvoinnin tutkimuskeskus, PL 57, 00014 Helsingin Yliopisto, \\ etunimi.sukunimi@helsinki.fi \\ $\left.{ }^{3}\right)$ Helsingin yliopisto, Kliinisen tuotantoeläinlääketieteen laitos, PL, 57, 00014 Helsingin Yliopisto, \\ etunimi.sukunimi@helsinki.fi
}

\section{Tiivistelmä}

Erilaiset jalkaviat ovat nykyisin hyvin yleisiä lypsykarjoissa. Ne aiheuttavat lehmille kipua ja tilalle suoria sekä epäsuoria kustannuksia. Epäsuorat kustannukset aiheutuvat lehmien heikentyneestä hedelmällisyydestä, kunnon heikkenemisestä ja tuotoksen laskusta. Luotettavia menetelmiä ontumisen mittaamiseen on käytössä vain vähän.

Me suunnittelimme ja rakensimme uuden langattoman kolmiulotteisen kiihtyvyysmittarin ja käytimme sitä lehmien kävelyn mittaamiseen 25 Hz:n mittaustaajuudella ja 6 g:n herkkyydellä. Mittarit lähettivät dataa 869 MHz:n radiokanavalla ja mittausdata tallennettiin vastaanottimen kautta tietokoneelle tutkimuksessa kehitetyn tietokoneohjelman avulla. Lähetys toimi luotettavasti navettaolosuhteissa käyttämällämme radiotaajuudella.

Tässä kokeessa mittasimme 5 terveen ja 6 ontuvan Ayshire-rotuisen lehmän kävelyä kehitetyllä mittarilla 20 sekunnin yhtäjaksoisen kävelytyksen ajan. Kiinnitimme yhden anturin lehmän jokaiseen jalkaan nilkan korkeudelle. Lehmien ontuminen määritettiin viisiportaisen visuaalisen ontuma-asteikon avulla niiden kävelystä ennen mittauksia.

Laskimme jokaisen akselin ja kiihtyvyyksien summan varianssin ja wavelet varianssin $R$ (2.81) tilasto-ohjelmalla käyttäen wmtsa - kirjastoa. Me löysimme tilastollisesti merkitseviä eroja takajalkojen askelten eteenpäin suuntautuvan akselin varianssin ja wavelet varianssin ensimmäisen tason (D1) symmetriassa ontuvien ja terveiden lehmien välillä. Wavelet varianssin ensimmäinen taso (D1) kertoo $40 \mathrm{~ms}$ skaalassa tapahtuneista muutoksista ja liittyy kävelyn maahan tulovaiheeseen ja heilautusvaiheen suurimpiin kiihtyvyyksiin.

Kehitimme uuden menetelmän mitata ja analysoida lehmien kävelyä ja todensimme sen soveltuvuuden mittaamalla ontumien ja terveiden lehmien kävelyn eroavaisuuksia. Laitteen etu nykyisiin teknologisiin menetelmiin verrattuna on, että sillä voidaan mitata ontumista nykyistä pidemmillä mittauksilla. Jatkotutkimuksissa pyrimme osoittamaan, että laiteella voidaan mitata ontuman vakavuutta nykyisiä menetelmiä tarkemmin.

Asiasanat: Lypsykarja, ontuminen, kiihtyvyysanturi 


\section{Johdanto}

Lypsylehmien ontuminen on yleinen lehmien hyvinvointia heikentävä ongelma. Ontuminen on kivun oire (Whay ym. 1997). Ontuminen myös heikentää lehmien hedelmällisyyttä (Garbarino ym. 2004) sekä tuottajan taloudellista tulosta (Enting ym. 1997). Tuottajat ovat tietoisia vain $25 \%$ tiloilla esiintyvistä ontumista (Whay ym 2003).

Ontumisen havainnointiin on kehitetty erilaisia menetelmiä, joissa havainnoidaan $\mathrm{mm}$. eläimen liikkumiskykyä, askelväliä, ontumisen määrää (Sprecher ym 1997, Manson ja Leaver 1988, Winckler \& Willen. 2001). Järjestelmien käyttö vaatii paljon harjoittelua ja tulokset ovat havainnoitsijasta riippuvaisia (Winckler \& Willen 2001)

Ontumisen havainnoinnin helpottamiksi on kehitetty myös erilaisia teknologisia menetelmiä; Pastell (2007) kehitti lypsyrobottiin nelivaakajärjestelmän, joka punnitsee lypsyn aikana erikseen lehmän jokaiselle jalalle kohdistuvan painon. Järjestelmään asennettu neuroverkkomalli tunnistaa lehmän kaikki varhaiset jalkaongelmat ja näin ollen jalkavikoihin voidaan puuttua ajoissa. ja parantaa taloudellista tulosta. Kaikki ontumista aiheuttavat jalkaongelmat eivät kuitenkaan näy seistessä ja järjestelmä soveltuu ainoastaan robottitiloille.

Myös ontumisen mittaaminen kävelystä on ollut usean tutkimuksen kohteena. Rajkondawar ym. (2006) kehittivät voima-antureihin perustuvan ontumisen mittausjärjestelmän ja Flower ym. (2005) käyttivät kuva-analyysiä ontumisen mittauksiin. Molemmat järjestelmät vaativat kuitenkin erillisen mittauspaikan ja pystyvät mittamaan korkeintaan kaksi peräkkäistä askelta.

Tämän tutkimuksen tavoitteena oli rakentaa ja validoida langaton kiihtyvyysanturi lehmien ontumisen mittaamiseen. Tavoitteena oli, että laitteella voidaan mitata useampia peräkkäisiä askelia ilman erityistä rakennettavaa mittauspaikkaa.

\section{Aineisto ja menetelmät}

\section{Ontumaluokitus}

Koetta edeltävän päivänä Viikin tutkimus- ja koenavetan lehmille tehtiin ontumaluokitus käyttäen Winkler \& Willenin (2001) kehittämää viisiportaista ontumaluokitusjärjestelmää. Kokeeseen valittiin 11 Ay-rotuista lypsylehmää, joista 5 oli luokiteltu terveeksi (ontumaluokitus 1-2) ja 6 ontuviksi (ontumaluokitus 4-5).

Kokeen alkaessa kiinnitimme langattoman kiihtyvyysanturin joustavalla siteellä eläimen jokaiseen jalkaan nilkan korkeudelle. Eläimet kävelytettiin yksitellen vähintään $20 \mathrm{~m}$ matka kumisella ruokinta käytävällä, ja analyysiin valittiin 20 sekunnin yhtäjaksoisen kävelytyksen mittaustulos.

\section{Mittalaite}

Tutkimuksessa rakennettiin langaton, kolmen akselin suhteen kiihtyvyyttä mittaava laite. Laite ohjelmoitiin lähettämään mittausdataa $25 \mathrm{~Hz}: n$ mittaustaajuudella 869 MHz:n radiokanavalla, $25 \mathrm{~Hz}: n$ mittaustaajuudella ja 6g:n mittausalueella. Mittausdata tallennettiin vastaanottimen kautta tietokoneelle tutkimuksessa kehitetyn tietokoneohjelman avulla.

\section{Aineiston analysointi}

Mittauksista saatiin lehmän jokaiselle jalalle vaaka-, pysty-, ja sivuttaissuuntainen kiihtyvyys anturin asennon suhteen. Jokaiselta lehmältä valittiin $20 \mathrm{~s}$ mittausjakso $(\sim 10$ askelta) analyysiä varten. Laskimme jokaisen akselin ja kiihtyvyyksien summan varianssin ja wavelet varianssin. Wavelet varianssi laskettiin 4:1le yksityiskohdalle $(D 1-D 4)$ ja se kuvaa aineistossa esiintyvää vaihtelua eri aikaskaaloilla. Käyttämällämme $25 \mathrm{~Hz}:$ m mittaustaajuudella komponentit $D_{1}, D_{2}, D_{3}$ ja $D_{4}$ vastaavat 40, 80, 160 ja 320 ms skaaloja. Analyysi on kuvattu tarkemmin julkaisussa Pastell el al. (2009).

Analysoimme rinnakkaisten jalkaparien (etu- ja takajalat) symmetrian laskemalla muuttujien suhteet seuraavasti: 


$$
\begin{aligned}
& S_{\text {var }}=\frac{\text { Variance }_{\text {min }}}{\text { Variance }_{\text {max }}} \\
& S_{D j}=\frac{D j_{\text {min }}}{D j_{\max }}
\end{aligned}
$$

missä $S_{\text {var }}$ on varianssin symmetria, Variance $_{\min }$ on jalkaparin pienempi varianssi, , Variance $_{\max }$ on jalkaparin suurempi varianssia, $S_{D j}$ on symmetria wavelet komponentille $j, D j_{\min }$ on jalkaparin pienempi $D_{j}$, ja $D j_{\max }$ on $D_{j}$ jalkaparin suurempi $D_{j}$.

Ontuvien ja terveiden lehmien symmetriaparametrien eroavaisuus testattiin Wilcoxonin järjestyslukutestillä. Analyysit tehtiin R (2.81) tilasto-ohjelmalla käyttäen wmtsa - kirjastoa.

\section{Tulokset}

Kuvassa 1 on esitetty terveen $(a, b)$ ja ontuvan $(c, d)$ lehmän takajalkojen eteenpäin suuntautuva kiihtyvyys 20 sekunnin kävelyn aikana. Ontuminen ei näy selvästi raakadatasta, mutta jalkojen varianssien suhteet eroavat selvästi ontuvan ja terveen eläimen välillä (d). Jalkojen maahantulo näkyy kuvassa terävinä piikkeinä.

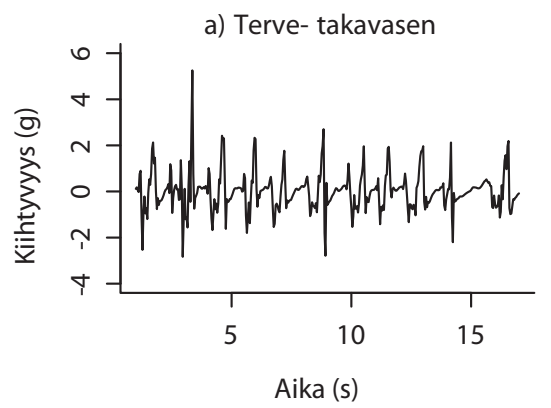

c) Ontuva - takavasen

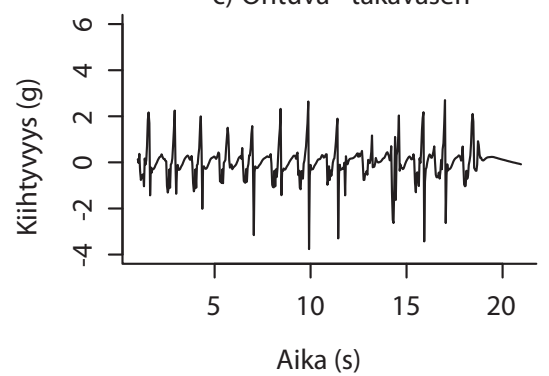

b) Terve - takaoikea

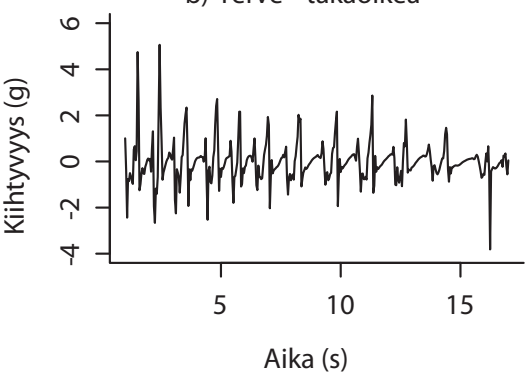

d) Ontuva - takaoikea

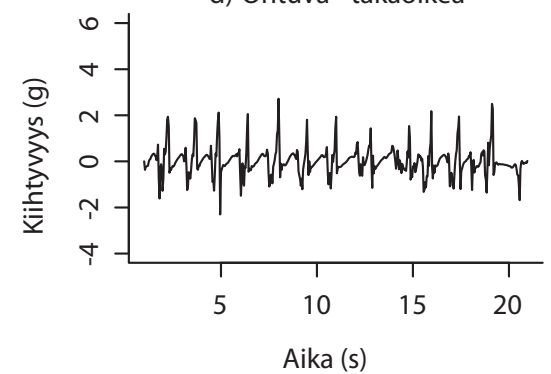

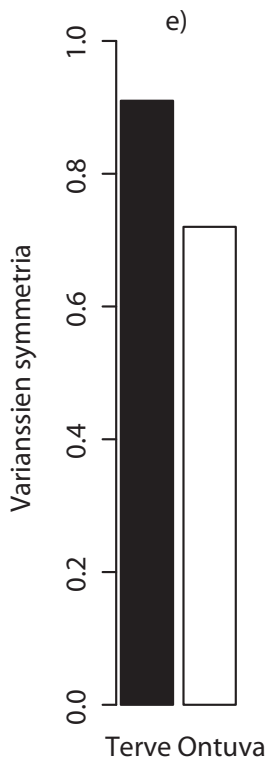

Kuva 1. Terveen $(a, b)$ ja ontuvan lehmän $(c, d)$ takajalkojen eteenpäin suuntautuva kiihtyvyys ja takajalkojen varianssin symmetria.

Ontuvien ja terveiden lehmien takajalkojen eteenpäin suuntautuvan kiihtyvyyden varianssien symmetriat $S_{\text {var }}$ erosivat merkittävästi $(\mathrm{P}<0.01)$ toisistaan (Kuva 1). Lisäksi Wavelet varianssin D1 komponentin, eli $40 \mathrm{~ms}$ aikaskaalan, eteenpäin suuntautuvan akselin symmetriat erosivat ontuvien ja terveiden lehmien välillä. Muissa symmetriaparametreissa ja akseleissa ei ollut eroa eläinryhmien välillä. 


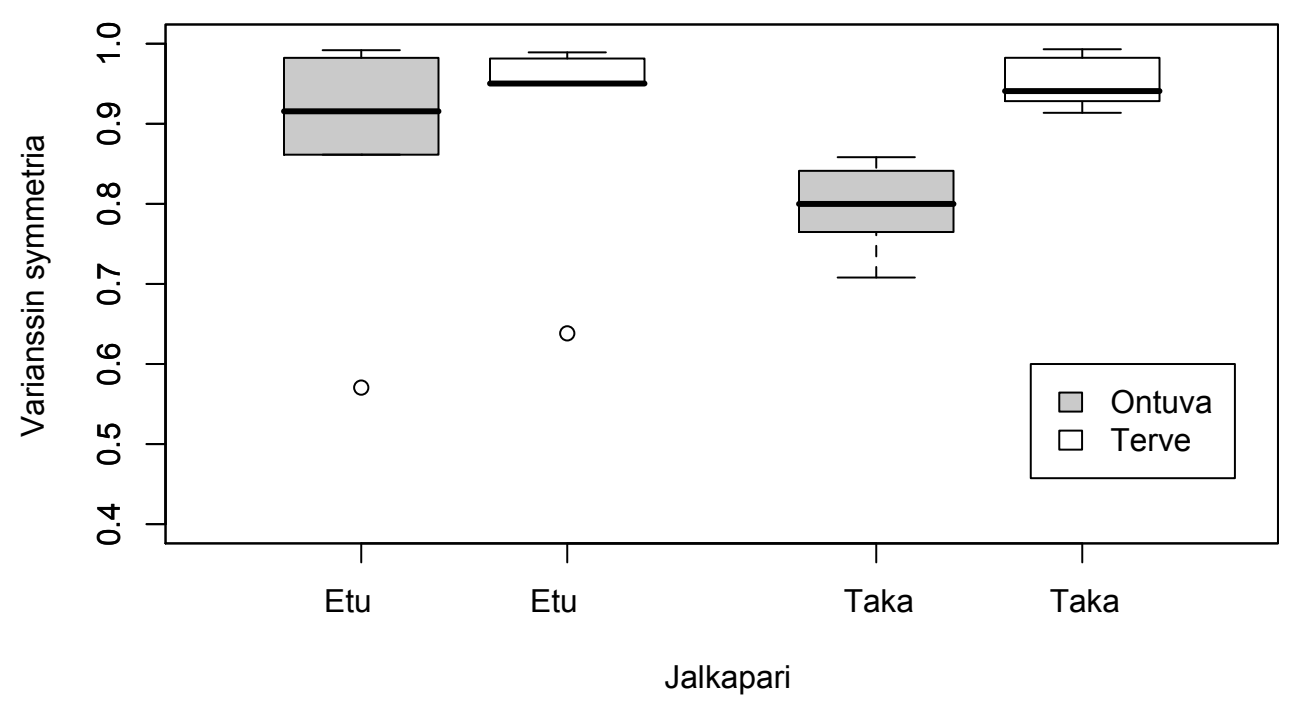

Kuva 2. Ontuvien ja terveiden lehmien etu- ja takajalkojen eteenpäin suuntautuvan kiihtyvyyden varianssien symmetria. Ryhmien takajalkojen välillä on tilastollisesti merkitsevä ero.

\section{Tulosten tarkastelu ja Johtopäätökset}

Me löysimme tilastollisesti merkitseviä eroja takajalkojen askelten eteenpäin suuntautuvan akselin varianssin ja wavelet varianssin ensimmäisen tason (D1) symmetriassa ontuvien ja terveiden lehmien välillä. Wavelet varianssin ensimmäinen taso (D1) kertoo $40 \mathrm{~ms}$ skaalassa tapahtuneista muutoksista ja liittyy kävelyn maahan tulovaiheeseen ja heilautusvaiheen suurimpiin kiihtyvyyksiin.

Kehitimme uuden menetelmän mitata ja analysoida lehmien kävelyä ja todensimme sen soveltuvuuden mittaamalla ontumien ja terveiden lehmien kävelyn eroavaisuuksia. Laitteen etu nykyisiin teknologisiin menetelmiin verrattuna on, että sillä voidaan mitata ontumista nykyistä pidemmillä mittauksilla. Jatkotutkimuksissa pyrimme osoittamaan, että laiteella voidaan mitata ontuman vakavuutta nykyisiä menetelmiä tarkemmin.

\section{Kirjallisuus}

Enting, H., Kooij, D., Dijkhuizen, A. A., Huirne, R.B.M. \& Noordhuizen-Stassen, E.N. 1997. Economic losses due to clinical lameness in dairy cattle. Livestock Production Science 49: 259-267.

Flower, F. C., Sanderson, D. J. \& Weary, D. M. 2005. Hoof Pathologies Influence Kinematic Measures of Dairy Cow Gait. Journal of dairy science 88 (9): 3166-3173.

Garbarino, E.J., Hernandez, J.A., Shearer, J.K., Risco, C.A. \& Thatcher, W.W. 2004. Effect on lameness of ovarian activity in postpartum Holstein cows. Journal of Dairy Science 87: 4123-4131.

Pastell, M. 2007. Automatic Lameness Detection in a Milking Robot : Instrumentation, measurement software, algorithms for data analysis and a neural network model. Doctoral dissertation University of Helsinki, Helsinki, $47 \mathrm{~s}$.

Pastell, M., Tiusanen, J., Hakojärvi, M. \& Hänninen, L. 2009. A wireless accelerometer system with wavelet analysis for assessing lameness in cattle. Biosystems Engineering 104 (4): 545-551.

Rajkondawar, P. G., Liu, M., Dyer, R. M., Neerchal, N. K., Tasch, U., Lefcourt, A. M. . Erez, B. \& Varner, A.M. 2006. Comparison of Models to Identify Lame Cows Based on Gait and Lesion Scores, and Limb Movement Variables. Journal of Dairy Science 89 (11): 4267-4275.

Whay, H. R., Main, D. C., Green, L. E. \& Webster, A. J. 2003. Assessment of the welfare of dairy cattle using animal-based measurements: direct observations and investigation of farm records. The Veterinary Record 153 (7): 197-202.

Whay, H. R., Waterman, A. E. \& Webster, A. J. 1997. Associations between locomotion, claw lesions and nociceptive threshold in dairy heifers during the peri-partum period. Veterinary journal 154 (2): 155-161.

Winckler, C. \& Willen, S. 2001. The Reliability and Repeatability of a Lameness Scoring System for Use as an Indicator of Welfare in Dairy Cattle. Acta Agriculturae Scandinavica, A 51 (Supplement 30): 103-107. 